\title{
Mobile communication and ethics: implications of everyday actions on social order
}

\author{
Rich Ling \& Rhonda McEwen
}

Of the many opportunities and affordances that mobile technologies bring to our day-to-day lives, the ability to cheat physical separation and remain accessible to each other-in an instant-also brings pressure to bear on well-established social conventions as to how we should act when we are engaged with others in shared spaces. In this paper we explore some ethical dimensions of mobile communication by considering the manner in which individuals in everyday contexts balance interpretations of emergent social conventions with personal desires to connect in the moment. As we later discuss, the decisions made in response to a ringing mobile phone or flashing text message emerge from consequential versus deontological ethical frames used to determine what to do versus what we ought to do. This is particularly true in western and North American cultural contexts from which our data are collected. Using Goffman's dramaturgy, we suggest that these conflicts occurring on an individual level provide evidence of social structure, and are simultaneously entwined with our less obvious ruminations on the maintenance of social order.

Keywords: mobile communication, emergent conventions, consequential ethics, deontological ethics, social order, reflexivity 


\section{The tension between the imperative of the individual and the moral rules of the collective, entangled by mobile phones}

If ethics is understood to fundamentally be about normative issues, and the development and justification of societal systems of moral rules (Chappell 1998; Dewey \& Hurlbutt 1977; Facione, Scherer \& Attig 1991), then alongside theoretical interests in the subject we should also examine the immediate implications of ethics on everyday human actions. The translation of ethics into everyday actions is observed in the decisions we make in daily life, in our sense of what is correct and incorrect behavior vis-à-vis others, and shows in tangible ways our sense of that which is ethical. In this paper we explore some ethical dimensions of mobile communication by considering the manner in which individuals in everyday contexts balance interpretations of emergent social conventions with personal desires to connect in the moment. As we later discuss, the decisions made in response to a ringing mobile phone or flashing text message emerge from consequential versus deontological ethical frames (Flew 1979; Olson 1967; Waller 2005) used to determine what to do versus what we ought to do. This is particularly true in western and North American cultural contexts from which our data are collected.

Our everyday decisions and actions are also a confirmation of the social order, as our interpretation of what is correct or incorrect behavior is relative to established social norms, conventions, and rules (Barbour 1992; Furrow 2005). By examining our ruminations on these rules, and our consequential actions based on individual value judgments, we gain insight into the sense of that which is social as opposed to that which is merely individual. The tensions that arise in decision-making processes expose the influence of ethics on the exercise of morals within social contexts. This is non-trivial and complex in daily, face-to-face interaction. Our ability to empathize with others who are near at hand can lead to better choices for the benefit of the collective and more altruistic outcomes. On the other hand, when we are more attentive to our individual desires and consciously or not become poorly attuned to those around us, our decisions can also lead to misunderstandings and abused feelings, and our actions may be interpreted as insensitive.

As we increasingly incorporate the use of technologies in our everyday interactions our decisions and actions become conflated and entangled with the affordances imbued in the technologies themselves (McEwen 2009; Orlikowski 2007). The ease with which technologies can facilitate certain actions plays a significant part in our decisions to act. For example, the availability of a car can influence a decision to make a particular dish for dinner if an essential ingredient is missing-we can simply take a quick drive to the 
market, instead of redefining the meal, which may have been the more likely outcome, or normative, ${ }^{1}$ in a pre-automobile era.

Mediated interaction via the mobile phone in particular adds new dimensions to ethical considerations. We often need to decide whether it is better to respect the sensibilities of co-present others over our desire to communicate with remote interlocutors when, for example, our phone rings in a restaurant. In this case the affordance of the mobile phone to dissolve geographical distance and provide virtual proximity presents the receiver with a choice in the moment-What should I do or not do?; Because I can answer does it mean that I must?; If I do not will the eventual telephonic partner be angry or suspicious? (Lasén forthcoming). While these are ethics that can be worked out by ponderous thought, we also need to process these issues in the moment. In mobile-mediated interactions, decision-making processes are further compounded by what may be described as incompatibilities in values (Berlin 1980). An incoming call in a restaurant places the value that an individual holds in being accessible at all times in conflict with a value that he or she has in being solely attentive to a dinner companion: this example illustrates basic tensions of pervasiveness versus limitedness, and being individual versus social. These decisions are also affected by the relative newness of mobile technologies and a perception that social rules and principles are still being worked out regarding the use of these technologies in various contexts. By understanding the principles governing our application of everyday ethics in these situations (both co-present and mediated) we have the opportunity to see the workings of society: society constituted as both the primary source of our ethical norms and behaviors, and society as reflected in the social contexts in which these norms and behaviors emerge reflexively through praxis.

Modern society is quite often focused on the individual and is, indeed, becoming more individualized. We see this in the sense that we need to construct and take responsibility for our own lives (Beck \& Beck-Gernsheim 2002; Lash 2002). At a more mundane level, the drift of technology development is in the direction of more individualized devices. Where there was public transportation, there is now personal transportation; where there were shared landline telephones, we now each have our own mobile phone. The mobile phone is clearly a part of this drift towards individualism. The mobile phone gives users freedom of movement. It is our own personal communication channel. It is a device where we can collect personal photos, our contact list, messages from friends and family, etc.

Even while individualization is a major organizing theme in society, another dynamic is being accessible to one another. While on the one hand, technology and the general drift of society is encouraging individualism, those technologies through which we mediate communication carry with them the expectation of being social. It is fair to say that the mobile phone 
is a personal device, but it is just as fair to say that it makes us individually addressable to others (Ling \& Donner 2009).

With personal addressability, there also comes responsibility. This is the paradox of being individually accessible. The freedom afforded by the mobile phone is not ours alone. All others who have a phone can call us as needed. Thus, the rise of individual addressability is also the rise of general availability and ambient accessibility, where we appear to be «always on" (Baron 2008). On the one hand the mobile phone gives us freedom and on the other hand it places us more securely in our social networks. We are not tied to a landline phone awaiting an important call. We can go about our daily chores regardless of where they might be. If it is more pleasant to be outside in the park while we await a call from an important business connection or our paramour, it is not a problem (i.e., where ownership and access to a mobile device is possible, as is increasingly the case globally ${ }^{2}$ ). The mobile phone gives us that freedom. But it also ties us into our social network. This is seen in the comments of an informant in a 1995 interview who was on the point of buying a mobile phone, but with reservations:

Kjell: $^{3} \mathrm{I}$ am a little against it but I have accepted that it has come to be and [I] will buy one for private use and I buy it actually just to have one. [...] [I] travel a little and will have it in the car because of security. I travel with my job [...] It enslaves me, the mobile phone. When you were free and you sat in the car and it rang. Actually, I don't have anything against the mobile phone. I have accepted its ugliness.

Kjell saw that the device provided him with freedom of movement and it also allowed him to travel between different locations. It provided security and it was also likely a coordination tool. However, it also was a control device. It gave him freedom but it also tethered him. He could experience individualism because of the phone and it also tied him to his social obligations. Kjell's comments show that from early on in its diffusion into society, people have recognized that that the mobile phone ties us to our social sphere for better and for worse. Indeed, a major finding of the mobile communication research community to date is that the mobile phone has resulted in tighter ties within the sphere of our closest friends and family Ling 2008; McEwen 2009).

This individual/social tension in the understanding of the mobile phone is obvious in an analysis of US teens. There is the sense that the mobile phone has a central place role in helping to maintain contact with friends and family, contact that can be described as a beneficial burden. A factor analysis, a statistical method of reducing a larger number of questionnaire items into a smaller number of underlying "factors» that have a certain internal consistency, shows the dual nature of mobile telephony. In the case of mobile phones, there is a sense that having a mobile phone is a way for an individual to stay in touch with important people in their social network and it is also a 
burden to have a mobile phone. As can be seen in Table 1, the first factor describes users' sense that the mobile phone gives them access to one another. The specific items describe how the teens can be in touch with parents as well as other persons in their social world. More than 90 percent of the teens were in agreement with these statements. This is the most important and the most obvious factor in the analysis and best describes the respondents' sense of the situation. Interestingly, the second factor describes the potential disruptions and the price to be paid for having a mobile phone. In this case, the respondents agreed with statements, saying that it was irritating to receive calls and that it was a burden to always have their mobile phone with them. These two factors are quite telling. They show that teens see the mobile phone as a way to access their parents and members of their social circle but, as Kjell commented, such access comes at a price. Finally, the third factor reflects more ego-based use of the mobile telephone, namely as a way to hold boredom and potential threats to safety at bay. While the first two factors can be, to some degree, interpreted as being located more in the social sphere, the third factor describes the more personal side of mobile communication, namely as a buffer against boredom, and as a safety link.

Table 1. A factor analysis showing the clustering of questionnaire battery items for US teens in 2009. A principle components analysis was used with varimax rotation based on an eight-item battery in the Pew survey from 2009 on teens and mobile communication based on 1304 teens (Lenhart et al. 2010). The rotation converged in five iterations. The component scores indicate the weight with which each item loaded on to a particular factor. Factor weights below 0.25 are not shown.

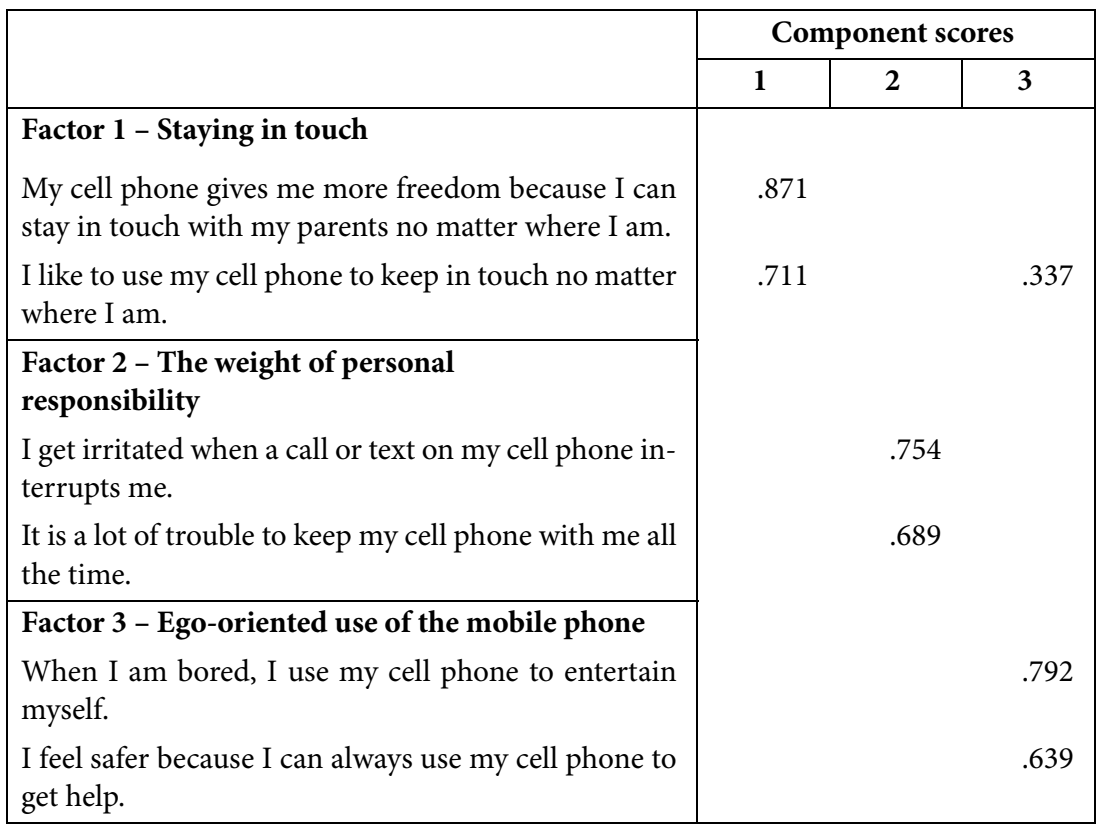


The statistics presented in Table 1 show that the respondents saw the mobile phone as both a social and an individual device. On the one hand, they saw it as a link to important people in their lives, albeit a link with a certain baggage. On the other hand, it was the locus of personal activities such as a way to be entertained and to ensure personal safety. In the remainder of this paper we look at the former of these two dimensions, namely the social nature of mobile telephony, and how our interpretation of ethical use of these communication devices in everyday contexts takes into consideration the maintenance of, and is in itself evidence of, social structure.

\section{Ethics as evidence of social structure}

One way to understand social interaction and decision-making processes is to look at reflexivity. That is, we structure our behavior based on how we expect others will react. Likewise, we expect that others will also structure what they do, at least to some degree, based on their estimation of how we will react. This is particularly true of those with whom we are close and with whom we have developed a sense of trust. Using this mechanism, over time we establish an internalized moral sense of correct and incorrect behavior. This guides our choices so that we may reflect that, «in this type of situation my friend likes it when I do X», and act accordingly.

From the perspective of ethics, our sense of what ought to be done is intimately interwoven with and manifest in our expectations regarding our own and others' behavior. In the case of mobile phones, the burden on the individual to come to the "right» conclusion is intensified by nascent social rules of mobile communications. We may not draw confidently from our sense of what others are doing in similar situations, since this is not yet consistent. Thus, we attempt to apply our ethical framework in our daily life to emergent situations. We draw on this internalized ethical framework in choosing how to tackle different issues as they arise. As we draw on our internalized moral sense of correct and incorrect behavior most of us would want to be mindful that there may be a distinction between what ought to be done and what others are doing. When election time comes around, we choose whether we should vote or abstain. When we are interrupted while talking we choose whether we should continue speaking and try to retain the floor or whether we should capitulate. When boarding a plane, we consider how others would see us if we rush to the front of the line or to let others come first. When passed a plate of fried chicken, we might consider what our dining partners would think of us were we to take the largest piece instead of a more moderate one. In each case our decision is, to some degree, calibrated by how we think others see us and also how we ourselves want to be treated (Duncan 1970). This reflexive dimension to interaction 
means that our behavior is not simply driven by a set of internal needs and drives; in making our decisions to act we draw on our internalized sense of that which is correct and incorrect. Our reflectivity incorporates our obligation toward others in the decision process. This is in itself developed through our social interaction and our understanding of how we feel that others see our behavior. The exercise of these everyday ethics is a confirmation of our social nature where such sociation ${ }^{4}$ is not simply a kind of stimulus-response conditioning, but an ethically-informed joining together.

Mobile communication has become an element in this. The mobile phone extends the sphere of social interaction. It is not simply co-present others who are affected by our use of the mobile phone. We can call and are called by others who are beyond the local setting. Thus, the situation of our remote interlocutor inserts itself into our co-present affairs. We choose to answer or not answer incoming phone calls based on our sense of propriety. For example, while we might not take most calls in a restaurant or classroom-if we are expecting a message from a sibling about our parent who is in a serious condition in hospital, we most certainly would take the call and/or respond to the SMS. The choices we make in these situations are derived from our reflexive sense of the social order and they, in turn, reconfirm that very social order. Our nascent rules of courtesy and ethics associated with mobile phone use describe our broader embedding in society. By tracing the ethics of how we use the mobile phone and our judgment ${ }^{5}$ of other's use in everyday interactions, we are indeed tracing the workings of society. Respondents in various studies have commented on the way that the mobile phone inserts itself into a local interaction, and also the issues of how a telephone or text interaction is played out.

\section{Mobile telephony and collocated interaction}

The mobile phone ringing while we are talking with others has become a standard feature of society. It is almost to be expected given the diffusion of the device. With face-to-face interaction we have a variety of visual cues with which to indicate to a person requesting a chat that it is not an appropriate moment for an interruption. We can avoid their gaze (something that waiters are adept at), we can turn our body away from the person who wishes a chat, we can hold up our hand to indicate that we need a moment to make the transition or we can simply say something like, «can you wait just a second while I finish up here.» All these, and many other stratagems are available in collocated interaction. The repertoire of social ploys is much more limited with an incoming mobile phone call. These often boil down to somehow parking the local interaction and either accepting or rejecting the call. While we are beginning to have some sense of how to approach this 
situation, it still means that we need to mobilize our sense of correct and expected behavior.

First-year university students interviewed by Rhonda McEwen in Toronto, Canada, illustrate this (McEwen 2009). By being put into the situation of needing to accept or reject the invitation for a chat, the students had to make a quick decision as to whether the co-present or the mediation interaction was most central.

The decision as to whether to prioritize the co-present or the mediated interaction had many elements, including issues such as who was calling and the importance or the engagement level of the co-present interaction. If a boss or a professor called, that would often trump the local discussion. However, to reject the call from a peer when the individual was engaged in an important meeting was judged to be a legitimate decision. Nonetheless, rejecting these calls was not guilt-free. The students described, for example, the guilt of screening the incoming calls of close friends. This violated, at some level, their sense of integrity. There was the idea that they had engaged in a deception that was inconsistent with their own sense of self. Looking at this from the perspective of reflexivity, the students were perhaps able to empathize with the frustration or the bewilderment of their unanswered interlocutors.

To play on Goffman's phrase, the specific challenge of the mobile phone is that it asks us to act on a double front stage (Goffman 1959; Ling 1997). We need to take into account the sensibilities of both our local and remote audiences. If, for example, the local group with whom we are talking insists on our attention, then it is more difficult to heed the needs of our eventual telephonic partner. One of McEwen's respondents said:

Then, let me see. I know, usually whenever we get a call, everybody's just like who is it. I'll flip the phone open and we'll all look at it and I'll look at their faces, should I pick it up or not, and I'll look at their faces, cause they have an impact on who I talk to, too, eh. So, if we do our little thingy [participant smiles while shaking her head], you know, forget it. (McEwen 2009: 184-185)

Answering the mobile phone in these situations puts us into a bind: Whom do we prioritize and of whom do we ask forbearance? In the above-mentioned study participants navigated these shoals by applying an ethical framework that, in this case, is more utilitarian or consequentialist in approach, contrasted with a more deontological approach where they would have considered to whom they had a moral duty (Flew 1979; Olson 1967; Waller 2005). Using consequential reasoning, participants demonstrated a focus on the effects or outcomes of their decisions. They estimated the eventual damage done to the relationship with the different conversation partners (the local and the telephonic). We contrast this with more deontological reasoning, which might have insisted that, for example, there was a moral 
duty to respond to a romantic partner's call, regardless of the ensuing fury of the person with whom they were currently co-located. In the studies that we reference in this paper, we identify a greater focus on consequences in participants' ethical reasoning. In general, regarding mobile communication, it appears that we do take into account that the sensibilities of copresent friends may be abused when we decide to talk to a telephonic partner. In addition, we might neglect the sentiments of the others who are simply within earshot (Monk et al. 2004). We have all felt that we have been wronged by the bore who insists on continuing their phone call in the elevator, on the bus or in some other small enclosed space. The reactions of «bus uncles» ${ }^{6}$ and the construction of urban legends (Ling forthcoming) show that the use of mobile telephony in public situations has not gone unnoticed. Such reactions have been broadly discussed and will eventually be included in our sense of correct use in public. We react when others violate the public decorum and think twice before doing it ourselves. It is in this situation that texting may (incorrectly) appear to be a better solution.

In many cases the co-present interaction has a type of entrenched right of way when compared to talking on the phone. To the degree that we are engaged in a collocated discussion, the ringing of a mobile phone is a disturbance. Regardless of the eventual urgency of the call, the ringing of a mobile phone when we are engaged in a discussion disrupts the flow of the social interaction and sharply refocuses attention on the individuals as separate entities. The resultant social fracture and feelings of discomfort are rooted in an ethical framework grounded in maintaining social order: a harmony of the whole. Rituals and social etiquette often provide bases to prioritize that which is happening in the co-present moment or locale. Indeed, almost all rules of etiquette (how to eat soup, how to greet a person, the type of clothes to wear at a funeral, or the order of a reception line at a wedding) govern our interpretations of how we should or ought to act in the local situation. There is an emergent etiquette of telephone use (albeit culturally specified), but the depth and breadth of manners are focused on collocated interaction. Given these considerations, and the ethical frame at work, the local situation is often prioritized over telephonic interruptions.

\section{The ethics of choosing the channel}

Shifting the focus away from the mobile communication's impact on collocated situations, we will now focus on the ethical issues of mediated interaction. Employing an ethical sensibility when using mobile communication means that we might weigh the alternatives and how their use will be interpreted by our conversation partners. Again, our ensuing decisions and choices are largely dependent on the underlying ethical reasoning employed (e.g., consequential or deontological). This is seen in the somew- 
hat inconclusive ruminations of US teens considering the use of alternative forms of mobile communication:

Tiffany: [...] if [some of my friends] know that they have to talk about something that might be a little tough, they're in an argument with a parent or something like that, texting can be easier because you can think about how you want to respond. You are not just like on the spot on the phone when somebody drops some like big news and like «Ah, ah, I don't know how to respond to this.» Texting will give you some time.

Ben: $\quad$ You can delete things if you ... like, I would, if it is like a big issue I always reread it and go «Mmmm, maybe that is not the smartest thing to say.» Whereas in a real-time conversation you can't go «Oh, forget I said that.»

Anna: It makes it more easier. Especially with personal situations that you are going through, like if your friend is like «What's wrong?» you know, it's like easier than talking on the phone.

Cathy: See, I would rather, if I'm like pissed off or something, I would rather call my friends than text them about it. Because I'd rather hear them talking to me and being like «It's okay, everything is going to be fine» than have them say that ... like read that on a screen. It is less personal.

Robbie: Yeah, usually is there is some emotional crisis involved, I call them because it is just, it just doesn't have the same feel to it, you know, just text on a screen. Usually horribly formatted and completely ungrammatical text.

Tiffany: I think since calling requires more effort and more of your time, then it is taken better and more like a person caring for you than if it is just like a text. Because it is like «Oh yeah, I'm like eating dinner and watching a TV show and oh, I am just going to say [indistinct]» and calling, it is like you take time out of your day to sit and talk to somebody.

Ben: That's why I like to text more because I feel like text is more «Hey! I have a question or something, you know, get back to me when you can» whereas I feel a call is more "Talk to me now.»

Anna: Yeah, that's true.

Ben: Because you have to pick up right then and talk to them right then.

The teens did not really seem to reach any single conclusion, but they examined the positive and the negative aspects of talking versus texting. As they worked through this they drew on their sense of how their interlocutor would interpret the interaction. Would a more precisely formulated text 
message be better than the immediacy of a call? Would the call turn into a shouting match because one or the other conversation partner let slip a poorly formulated statement? Which form would be seen as more personal or more intrusive by the other? All of these issues are in the mix of responses given. They are all framed around an image of the other and the consequences of their potential response to the message.

Texting has certain advantages when compared to voice interaction. It provides a somewhat wider tolerance in its execution. Talking on the phone implies that we are engaged in the interaction. We have to insert verbal reminders to our interlocutor to let them know that we are still there and that we have not drifted off. In face-to-face situations, this can be done with gaze and different types of gestures. When on the phone we use grounding comments such as «Uhmm» and "Yeah» to indicate engagement (Clark \& Brennan 1991; Clark \& Schaeffer 1981; Clark \& Marshall 1981; Ling \& Helmersen 2000; Saks, Schegloff \& Jefferson 1974; Vaughn 1983). Texting relaxes these constraints:

Terry: You aren't as connected, you aren't as responsible [when texting]. Because having a phone conversation, especially with somebody who is not really close to you, sometimes I just feel that it takes more work, versus just texting. You have to try to keep the flow of a conversation, if there is silence you know you're trying to ... Um ... (Teen girl interviewed in 2009)

Terry indicates that texting reduces the commitment to the interaction. There is not the need to be as actively engaged. Maintaining the flow of the conversation is more work. Texting allows the interlocutors to wait a certain amount of time before responding and it also means that they can be engaged in other activities while the text interaction is taking place. Texting allows the interlocutors more space in the interaction and it also means that the threshold for contacting one another is lower (Licoppe 2004). Terry's ruminations with regards the difference between texting and talking show that she is of two minds. On the one hand, there is the desire for direct and perhaps more responsive contact. On the other hand, there are obligations to conversing. One has to listen to things that might be boring. The other person might dominate or interrupt. One has to continually indicate one's engagement, regardless of its interest (Vallor 2010). There is not a simple solution. Each situation and each interaction needs to be judged with regards to the most appropriate form of mediation. We need to gauge how our conversation partner will react to a series of texts versus a conversation. Will the texts be seen as genuine? Will it be too intrusive to call just to talk about trivial things when we know that they are stressed about making dinner? Will they have the sense that the interaction was appropriate? These are the dimensions that push us in one or the other direction. Given that we have an alternative we can always wonder whether we made the correct choice. 


\section{Counting on others' availability}

Given the diffusion of the mobile phone, we can reasonably assume that others are available. That is, either we know for a fact that they have a mobile phone or that we can reasonably assume that most people in a particular group have access to a mobile phone. When this critical mass is in place, we can make assumptions regarding their availability. We can begin to feel a certain right or privilege of access and perhaps feel a sense of indignation when they do not answer our calls (Lasén forthcoming).

Just as if the system of time and mechanical clocks were disrupted, the organization of society would become difficult (Simmel 1903/1971). Were the mobile system to be disrupted, it would have consequences for the functioning of social interaction (Wurtzel \& Turner 1977). On a personal level, if we forget our phone at home or do not charge the battery we are not acting responsibly in relation to our social network. We are somehow out of kilter with society and we are shirking the assumptions that others have. Indeed, in some particularly tense situations, if a person does not answer the phone when his or her partner calls it may signal that they have found another locus for their affections. Indeed, Lasén describes how some partners make a point of borrowing another's phone to call their partner when they have forgotten their own phone with the intention of ruling out this line of speculation (Lasén forthcoming).

We are just beginning to have socially consistent etiquettes regarding mobile telephony (Ling forthcoming; Nordal 2000). These etiquettes arise from processes of reflexivity occurring on at least two levels. Firstly, there is a social reflexivity that helps us to begin to establish generally agreed upon norms. That is, we are starting to form a generalized reflexive sense of what we expect of others and what others can expect of us (Duncan 1970: 69; Jackson 1952: 235). Secondly, there is the reflexive process that occurs in the local moment and calls on the individual to apply an ethical frame at that is consistent with what Duncan calls the image of the self (Duncan 1970: 266), and what Geertz describes as a reciprocally built sense of how to both govern our interactions and buffer us when annoying events arise (Geertz 1972; Gullestad 1992: 165). There is also the notion that the different participants in a situation approach it with a common understanding that allows them to muddle through (Goffman 1967: 65). While the finer points of use are still being constructed we have broad expectations of others, and they of us. Further, we are starting to be able to understand and interpret others' use of the device. We know when others are being abrupt or superficial when using the mobile phone. We are starting to know the difference between a text message that is likely to be from a male as opposed to one that is likely to be from a female. In short, we are applying frames, cues, and expectations and starting to understand the social and ethical issues of mobile phone use. We are also able to discount, or at least interpret the «drunken» texts that 
might arrive late on a Friday night that show the a more unfiltered and less than flattering side of the person sending the text (Hollenbaugh \& Ferris forthcoming).

\section{Conclusion}

Mobile telephony provides insight into the workings of society. While there may be the sense that there is greater individualism in society, and indeed while the mobile phone is seemingly an element in this direction, it is also a tool of sociation. We use it to construct and to maintain social networks. More fundamentally, however, the mobile phone and our sense of its proper use expose our sense of that which is correct and our sense of our responsibility to others. Its pervasive presence in our day-to-day life means that mobile phones are increasingly entangled with our ethical and moral decisions in social interactions. In the flash decision to answer a call or to maintain the co-present conversation we draw on our sense of ethical behavior that has been developed reflexively in previous social interaction, and also in the process-reflexivity of the local moment. In deciding to call a friend or to text them, we also draw on the ethical framework that we have constructed through similar interactions, and our resultant actions demonstrate consequential or deontological (or other) underpinnings.

The mobile phone has quickly come into use in society. Because of this it has disturbed social rules and norms that have been crystallized over centuries. The fact that others can call us at will, and we can call them, and the fact that we are individually addressable, means that we have to rework the rules. These decisions are predicated on both individual and social values that are not always compatible, and this adds to the complexity within which we interact in mediated environments. In the decisions we make, in the contexts we negotiate, and through the technological affordances we enjoy, we indicate how we imagine others would like to be treated and we also indicate to others, in some way, our own preferences for their actions towards us.

\section{Notes}

1 The term «normative» can be used in either a statistical sense (i.e., what the majority of persons would do), or in a moral sense (i.e., what I ought to do). In this paper we apply both meanings of the term, as we argue that since social conventions regarding mobile communication are not yet «normative» in a statistical sense users must also base their actions on what they believe they ought to do from a moral perspective. 
2 We do not address the matter of digital divide in this paper; instead we focus on contexts where mobile phones are available to the majority of the general population.

3 Names used throughout this paper are pseudonyms to protect the identities of participants.

4 That is our proclivity to engage in social interaction and to keep company with others.

5 See Ess and Thorseth (in press) on virtue ethics and the notion of «judgement».

6 http://www.youtube.com/watch?v=EsYRQkmVifg

\section{Literature}

Barbour, I. (1992) Ethics in an age of technology. New York, NY: Harper Collins.

Baron, N. (2008) Always on: Language in an online and mobile world. New York, NY: Oxford University Press.

Beck, U. \& Beck-Gernsheim, E. (2002) Individualization: Institutionalized individualism and its social and political consequences. London: Sage.

Clark, H. \& Brennan, S. (1991). Grounding in communication. In Perspectives on socially shared cognition, eds. L.B. Resnick, J.M. Levine \& S.D. Teasley, pp. 127149. Washington DC: American Psychological Association.

Clark, H. \& Marshall, C.R. (1981) Definite reference and mutual knowledge. In Elements of discourse understanding, ed. A.K. Joshi, B.L. Webber \& I.A. Sag, pp. 10-63. Cambridge: Cambridge University Press.

Clark, H. \& Schaeffer E.W. (1981) Contributing to discourse. Cognitive science, 13, pp. 259- 295.

Duncan, H.D. (1970) Communication and the social order. London: Oxford.

Flew, A. (1979) Consequentialism. In A dictionary of philosophy, 2nd Ed, p. 73. New York: St. Martins.

Ess, C. \& Thorseth, M. (in press). Introduction. In Trust and virtual worlds: Contemporary perspectives. London: Peter Lang.

Geertz, C. (1972) Linguistic etiquette. In Readings in the sociology of language, ed. J.A. Fishman, pp. 282-295. The Hague: Mouton.

Goffman, E. (1959) The presentation of self in everyday life. New York: Doubleday Anchor Books.

Goffman, E. (1967) Interaction ritual: Essays on face-to-face behavior. New York: Pantheon.

Gullestad, M. (1992) The art of social relations: Essays on culture, social action and everyday life in modern Norway. Oslo: Universitetetsforlaget.

Hollenbaugh, E.E. \& Ferris, A.L. (forthcoming) «I love you, man»: Drunk dialing motives and their impact on social cohesion. In Mobile communication: Bringing us together or tearing us apart? The Mobile Communication Research Series, eds. R. Ling \& S. Campbell, vol. 2. New Brunswick: Transaction.

Jackson, T. (1952) Some variables in role conflict analysis. Social Forces, 30, pp. 323-327.

Lasén, A. (forthcoming) 'Mobiles are not that personal': The unexpected consequences of the accountability, accessibility and transparency afforded by mobile telephony. In Mobile communication: Bringing us together or tearing us apart? 
The Mobile Communication Research Series, eds. R. Ling \& S. Campbell, vol. 2. New Brunswick: Transaction.

Lash, S. (2002) Individualization in a non-linear mode. In Individualization, eds. U. Bech \& E. Beck-Gernsheim, pp. vii-xiii. London: Sage.

Lenhart, A., Ling, R., Campbell, S. \& Purcell, K. (2010) Teens and mobile phones. Washington DC: Pew Research Center.

Licoppe, C. (2004) Connected presence: The emergence of a new repertoire for managing social relationships in a changing communications technoscape. Environment and planning: Society and space, 22, pp. 135-156.

Ling, R. (1997) «One can talk about common manners!»: The use of mobile telephones in inappropriate situations. In Themes in mobile telephony Final report of the COST 248 home and work group, ed. L. Haddon, pp. 73-96. Stockholm: Telia.

Ling, R. (2008) New tech, new ties: How mobile communication is reshaping social cohesion. Cambridge: MIT Press.

Ling, R. (forthcoming) Taken for grantedness. Cambridge, MA: MIT Press.

Ling, R. \& Donner, J. (2009) Mobile communication. London: Polity.

Ling, R. \& Helmersen, P. (2000) «It must be necessary, it has to cover a need»: The adoption of mobile telephony among pre-adolescents and adolescents. Presented at the conference on the social consequences of mobile telephony, 16 June 2000, Oslo, Norway. Downloaded from http://www.itu.dk/ christie/ mobilspeciale/litteratur/Ling,\%20Rich\%20-\%20It\%20must\%20be\%20-necessary,\%20it\%20has\%20to\%20cover\%20a\%20need.pdf

McEwen, R.N. (2009) A world more intimate: Exploring the role of mobile phones in main-taining and extending social networks. Toronto: Faculty of Information, University of Toronto.

Monk, A., Carroll, J., Parker, S. \& Blythe, M. (2004) Why are mobile phones annoying? Behavior and Information Technology, 23, pp. 33-41.

Nordal, K. (2000) Takt og tone med mobiltelefon: Et kvalitativt studie om folks brug og opfattelrer af mobiltelefoner. Institutt for sosiologi og samfunnsgeografi, Universitetet i Oslo.

Olson, R.G. (1967) Deontological ethics. In The encyclopedia of philosophy, ed. P. Edwards, pp. 343-345. London: Collier Macmillan.

Sacks, H., Schegloff, E.A. \& Jefferson, G. (1974) The simplest systematics for the organization of turn-taking for conversations. Language, 50, pp. 696-735.

Simmel, G. (1903/1971) The metropolis and mental life. In Georg Simmel: On individuality and social forms, ed. D.N. Levine, pp. 324-399. Chicago: University of Chicago.

Vallor, S. (2010) Social networking technology and the virtues. Ethics and Information Technology, 12, pp. 157-170.

Vaughn, D. (1983) Uncoupling: The social construction of divorce. In Social interaction, eds. H. Robby \& C. Clark, pp. 405-422. New York: St. Martins.

Waller, B.N. (2005) Consider ethics: Theory, readings, and contemporary issues. New York, NY: Pearson Longman.

Wurtzel, A.H. \& Turner, C. (1977) Latent functions of the telephone: what missing the extension means. In The social impact of the telephone, ed. I. De Sola Pool, pp. 246-261. Cambridge: MIT Press. 